August 2002 - NREL/CP-520-33142

\title{
Narrow Gap a-SiGe:H Grown by Hot-Wire Chemical Vapor Deposition
}

\section{Preprint}

\author{
B.P. Nelson and Y. Xu
}

National Renewable Energy Laboratory, Golden, Colorado

D.L. Williamson

Colorado School of Mines, Golden, Colorado

D. Han

University of North Carolina at Chapel Hill, Chapel Hill, North Carolina

R. Braunstein, M. Boshta, and B. Alavi

University of California at Los Angeles, Los Angeles, California

To be presented at the $2^{\text {nd }}$ International Conference on

Cat-CVD (Hot-Wire CVD) Process

September 10-13, 2002

Denver, Colorado

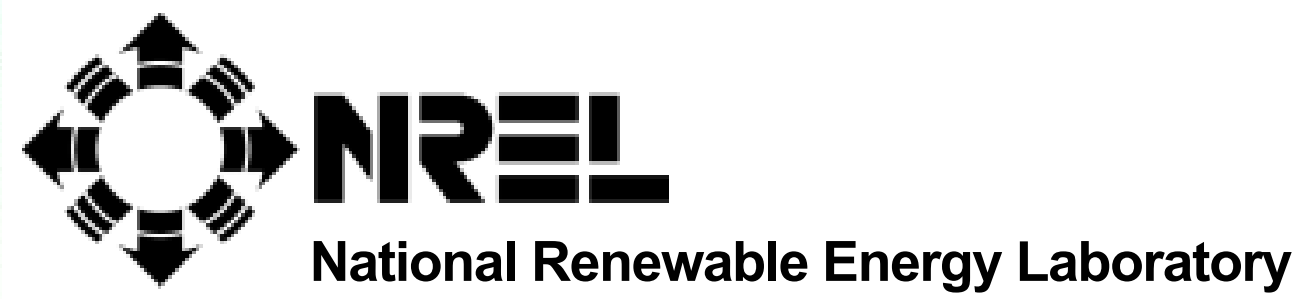

1617 Cole Boulevard

Golden, Colorado 80401-3393

NREL is a U.S. Department of Energy Laboratory

Operated by Midwest Research Institute • Battelle • Bechtel

Contract No. DE-AC36-99-G010337 


\section{NOTICE}

The submitted manuscript has been offered by an employee of the Midwest Research Institute (MRI), a contractor of the US Government under Contract No. DE-AC36-99G010337. Accordingly, the US Government and MRI retain a nonexclusive royalty-free license to publish or reproduce the published form of this contribution, or allow others to do so, for US Government purposes.

This report was prepared as an account of work sponsored by an agency of the United States government. Neither the United States government nor any agency thereof, nor any of their employees, makes any warranty, express or implied, or assumes any legal liability or responsibility for the accuracy, completeness, or usefulness of any information, apparatus, product, or process disclosed, or represents that its use would not infringe privately owned rights. Reference herein to any specific commercial product, process, or service by trade name, trademark, manufacturer, or otherwise does not necessarily constitute or imply its endorsement, recommendation, or favoring by the United States government or any agency thereof. The views and opinions of authors expressed herein do not necessarily state or reflect those of the United States government or any agency thereof.

Available electronically at http://www.osti.gov/bridge

Available for a processing fee to U.S. Department of Energy and its contractors, in paper, from:

U.S. Department of Energy

Office of Scientific and Technical Information

P.O. Box 62

Oak Ridge, TN 37831-0062

phone: 865.576.8401

fax: 865.576.5728

email: reports@adonis.osti.gov

Available for sale to the public, in paper, from:

U.S. Department of Commerce

National Technical Information Service

5285 Port Royal Road

Springfield, VA 22161

phone: 800.553 .6847

fax: 703.605.6900

email: orders@ntis.fedworld.gov

online ordering: http://www.ntis.gov/ordering.htm

Printed on paper containing at least $50 \%$ wastepaper, including $20 \%$ postconsumer waste 


\title{
Narrow Gap a-SiGe:H Grown by Hot-Wire Chemical Vapor Deposition
}

Brent P. Nelson ${ }^{1}$, Yueqin Xu ${ }^{1}$, D. L. Williamson ${ }^{2}$, Daxing $\mathrm{Han}^{3}$, Rubin Braunstein ${ }^{4}$, M. Boshta ${ }^{4}$, and B. Alavi ${ }^{4}$

\author{
${ }^{1}$ National Renewable Energy Laboratory, 1617 Cole Blvd., Golden, CO 80401-3393, USA \\ ${ }^{2}$ Department of Physics, Colorado School of Mines, Golden, CO 80401, USA \\ ${ }^{3}$ Department of Physics \& Astronomy, University of North Carolina at Chapel Hill, \\ Chapel Hill, NC, 27599-3255, USA \\ ${ }^{4}$ Department of Physics and Astronomy, University of California, Los Angeles, \\ Los Angeles, CA, 90095, USA
}

\begin{abstract}
We have improved the quality of our narrow bandgap a-SiGe:H grown by hot-wire chemical vapor deposition (HWCVD) by decreasing our W filament diameter and our substrate temperature. We now grow a-SiGe:H with Tauc bandgaps below $1.5 \mathrm{eV}$ having a photoresponse equal to or better than our plasma enhanced CVD grown alloys. We enhanced the transport properties - as measured by the photoconductivity frequency mixing technique-relative to previous HWCVD results. These improved alloys do not necessarily show an improvement in the degree of structural heterogeneity on the nanometer scale as measured by small-angle x-ray scattering. Decreasing both the filament temperature and substrate temperature produced a film with relatively low structural heterogeneity while photoluminescence showed an order of magnitude increase in defect density for a similar change in the process.
\end{abstract}

Key Words: Silicon, Germanium, Alloy, Hot-Wire 


\section{Introduction}

This paper is a companion to the one by Y. Xu et al. [1], where she describes the changes made to the deposition processes to improve the material properties of narrow gap a-SiGe:H alloys. Narrowing the bandgap of a-SiGe:H alloys by increasing the Ge content also decreases the film quality. For example, both the defect density and the Urbach energy increase with increasing Ge content [3]; other properties, such as the photoresponse [2] and the structural homogeneity on the nanometer scale decrease [4]. This is due partly because the void density increases, and partially because the Ge distribution fluctuates with in the film [5]. The ambipolar diffusion length decreases [6] with increasing Ge. It is difficult to passivate Ge-dangling bonds (with $\mathrm{H}$ ) as the Ge content increases [7], leading to poor film quality in films with narrow bandgaps.

Our early attempts to grow a-SiGe:H at high deposition rates (over $10 \AA / s$ ) were promising at Tauc gaps over $1.5 \mathrm{eV}$, but our films with narrower gaps were of poor quality [6]. Matsumura reported similar results for a-SiGe:H grown by hot-wire chemical vapor deposition (HWCVD) in the late 1980's [8]. We since decreased both the filament diameter and the substrate temperature improved the photoresponse of our narrow bandgap a-SiGe:H [1], we grew a series of samples for a variety of material characterizations reported in this paper.

\section{Experiment}

These samples were grown using a $0.38 \mathrm{~mm} \mathrm{~W}$ filament wrapped in a coil in our tube reactor with an isothermal heating zone. Germane and silane were the respective Ge and Si source gases. Hydrogen dilution was used at flows similar to the sum of the flows of the silane and germane $(\sim 25 \mathrm{sccm})$. Additional run details are in reference [1] and in Tables $1 \& 2$. 
The charge transport properties of the a-SiGe:H samples in the annealed state (2 hours at $150^{\circ} \mathrm{C}$ ) were characterized by using the photomixing technique at room temperature [10-12]. This technique enables a separate determination of the drift mobility $\left(\mu_{\mathrm{d}}\right)$ and the photomixing lifetime $(\tau)$ of the dominant photogenerated carriers. From the electrical field dependence of these quantities, the range and the depth of the long range potential fluctuations (LRPF), and subsequently the relative changes in the charged defect density in the films is determined. The longitudinal modes of a He-Ne laser were employed to generate the microwave difference frequencies. The beat frequency signal at $252 \mathrm{MHz}$ (photomixing angular frequency $\sim 1.58 \mathrm{GHz}$, corresponding to a time scale of $\sim 630 \mathrm{ps}$ ) was used as it has the highest intensity. Small-angle $\mathrm{x}-$ ray scattering (SAXS) was used to examine film heterogeneity. The experimental methods and data interpretation procedures are described elsewhere [13].

\section{Results and Discussion}

\subsection{Conductivity}

Figure 1 shows the results of conductivity measurements made on these samples. We increased the photo-to-dark conductivity ratio (photoresponse) of these alloys from our previous work as shown in the top frame of Figure 1. The dark conductivity increases somewhat uniformly with decreasing Tauc gap (bottom frame of Figure 1). It is difficult to consistently obtain high photoconductivities in these narrow gap alloys, as noted by the large scatter in photoconductivity in the middle frame of Figure 1 and the top frame of Figure 2. Samples with high photoresponses typically have a high photoconductivity. 


\subsection{Photoconductivity Frequency Mixing}

Figure 2 shows the photoconductivity (which is proportional to the $\mu_{\mathrm{d}} \tau$ product) as a function of the Tauc gap in the top frame, followed by the $\mu_{\mathrm{d}}$ and $\tau$ independently-also as a function of the Tauc gap —in the middle and bottom frames, respectively. In a previous study of a-SiGe:H by HWCVD, we were unable to obtain a good enough photoresponse from samples with enough Ge in them to lower the bandgap below $1.4 \mathrm{eV}$ and thus were not able to report on measurements using the photomixing technique for such narrow bandgap alloys [12]. This effort produced superior a-SiGe:H alloys to the previous study. Although both the $\mu_{\mathrm{d}}$ and $\tau$ have vastly smaller values than the a-Si:H reference (far right, $\sim 1.72 \mathrm{eV}$ data in Figure 1), they are at least measurable. The earlier data showed a decrease in the $\mu_{\mathrm{d}} \tau$ product correlating with a decrease in the photoconductivity. The current data are less correlated.

The bandgap (Ge) dependence of the mobility observed suggests that the LRPFs may be involved in the charge transport process. As Sheng et al. suggested [12], the decrease in drift mobility results from an increase in the charged scattering centers, which can be caused by LRPF. LRPF was evident because mobility increases with increasing applied electrical field and with increasing illumination intensity caused by screening [10]. The measurements of the electrical field dependence of mobility and lifetime show strong evidence for the presence of LRPF. We have calculated the range and depth of the LRPF, and show the results in Figure 3. As expected, the mobility decreases as the depth of the LRPF increases (see the "mirror" like dependencies with Tauc gap from the middle frames in Figures 2 and 3 respectively). The rapid increase in the depth of the LRPF with increasing Ge (lower Tauc gap) from our first study [12] is averted in this set of samples, further evidence of improved quality resulting from our new process [1]. 
The density of charged defects $(\mathrm{N})$ responsible for the LRPF can be estimated by:

$$
\mathrm{N} \propto \mathrm{V}_{\mathrm{p}}^{2} / \mathrm{L}
$$

Where $\mathrm{V}_{\mathrm{p}}$ represents the depth potential fluctuations and $\mathrm{L}$ represents the range of the potential fluctuations [11]. The bottom frame in Figure 3 shows the relative change in the charged defects as a function of Tauc gap. Clearly the charged defect density increases with increased Ge (lower Tauc gap).

\subsection{Photoluminescence}

The PL peak energy position at $80 \mathrm{~K}$ is presumably correlated to the optical gap, and the relative efficiency is inversely proportional to the density of defects. Figure $4 \mathrm{a}$ shows the relative intensity of PL as function of photon energy at $80 \mathrm{~K}$ for samples L743, L744, and L745. The peak intensities that are obtained from this figure and are summarized with key deposition data in Table 1. In order to compare the PL spectral line shape, we plotted the normalized PL spectra in Figure 4b, from which we get PL peak energy positions (Table 1). This correlates with the optical gap as expected.

The relative PL intensity of sample L744 is only about $30 \%$ less than that of sample L743, whereas the PL peak energy decreased about $0.1 \mathrm{eV}$. The higher Ge content of L743 reduces the optical gap, and the defect density increases slightly, relative to L744. 
L745 has an order of magnitude larger defect density than L744. L745 was grown by reducing both the filament temperature and the substrate temperatures from L744. We light soaked all three samples with an in-situ $100 \mathrm{~mW} / \mathrm{cm}^{2}$ white light for 2 hours. There were no obvious changes of the PL spectra before and light soaking for samples L743 and L744, but there was a $30 \%$ increase of the PL relative intensity for sample L745 as shown in Figure 5. Usually the PL intensity at $80 \mathrm{~K}$ has no obviously change, or a slight decrease, when metastable defects were created. If the structure changes and defects are created take place in a non-homogeneous film, the PL intensity could increase [15].

\subsection{Small Angle X-ray Scattering}

Figure 6 shows SAXS scans for a set of alloys grown under conditions similar to those discussed earlier (Table 2). There is a systematic increase in the SAXS intensity with increasing Ge content of the film, except for L828 which has the smallest intensity of this set. Figure 7 shows the integrated SAXS intensity, $Q_{N}$, as a function of the Tauc gap for each sample (top frame). $Q_{N}$ is a measure of the total electron density fluctuations in the film [13] and correlates to changes in film uniformity caused by nanovoids or Ge concentration fluctuations [5]. An increase in $\mathrm{Q}_{\mathrm{N}}$ implies an increase in the nanostructural heterogeneity. Consequently, either void density or Ge non-uniformity, or both, will increase. We know from previous work (dashed line), that the nanostructural heterogeneity displays a sharp increase at bandgaps $\leq 1.5 \mathrm{eV}$. The current samples have bandgaps below this transition and hence have large $\mathrm{Q}_{\mathrm{N}}$. We model the SAXS data using spherical objects, of an average diameter $<\mathrm{D}>$ as the cause of heterogeneity in the films [13].

The values for $<\mathrm{D}>$ for these films are presented in Table 2 and are only somewhat smaller than the range of the LRPF deduced from the photomixing technique (Figure 3, top frame). 
In the middle frame of Figure 7 we see that this set of films has a similar photoresponse to our previous narrow gap alloys grown at higher deposition rates (dashed line), except for L828 (which has a very high value for the gap of $1.25 \mathrm{eV}$ ). In the bottom frame of Figure 7 we see that Urbach energy $\left(E_{U}\right)$ as measured by the constant photocurrent method shows a systematic increase with decreasing Tauc gap, again with the exception of L828, which has a lower $\mathrm{E}_{\mathrm{U}}$ than the trend. The anomalous sample-L828 - was grown with a lower substrate temperature $\left(150^{\circ} \mathrm{C}\right)$ and a lower filament temperature $\left(1800^{\circ} \mathrm{C}\right)$ than the others.

\section{Conclusions}

We used a variety of measurement techniques to confirm that we have improved the material quality of our narrow bandgap a-SiGe:H alloys. We can now measure the transport properties of alloys with Tauc gaps below $1.45 \mathrm{eV}$ using the photoconductivity frequency mixing technique. Improvements in the photoresponse for one very narrow Tauc gap film (L828) were accompanied by lower values of both $\mathrm{E}_{\mathrm{U}}$ and $\mathrm{Q}_{\mathrm{N}}$ relative to trends of increasing values with increasing Ge alloying. This sample was grown by lowering both the filament temperature and substrate temperature relative to other films in this series (all grown with the smaller filament diameter of $0.38 \mathrm{~mm}$ ). A similar change in the deposition conditions for a sample prepared for

photoluminescence measurements (L745) resulted in an order of magnitude increase in defect density and a 30\% increase in the PL relative intensity with light soaking; however, this sample had a lower photoresponse than the SAXS sample. 


\section{References}

1. Y. Xu, B.P. Nelson, L.M. Gedvilas, and R.C. Reedy, September 2002, $2^{\text {nd }}$ International Conference on Cat-CVD (Hot-Wire CVD) Process, Denver, CO, submitted Thin Solid Films.

2. D. Cohen, NREL subcontract report SR-520-28050 (2000) (http://www.eren.doe.gov/pv/onlineind.html).

3. S. Wagner, V. Chu, D.S. Shen, J.P. Conde, S. Aljishi, and Z E. Smith, Mat. Res. Soc. Symp. Proc. Vol. 118, MRS, Pittsburgh, PA (1988) p. 623.

4. D.L. Williamson, Y. Xu, and B.P. Nelson, in M. Al-Jassim, J.P. Thornton, and J.M. Gee, eds., NCPV Photovoltaics Program Review, AIP Conf. Proc. No. 462, AIP, Woodbury, NY (1999) p. 272.

5. G. Goerigk and D.L. Williamson, J. Appl. Phys. 90 (2001) 5808.

6. B.P. Nelson, Y. Xu, D.L. Williamson, B. von Roedern, A. Mason, S. Heck, A.H. Mahan, S.E. Schmitt, A.C. Gallagher, J. Webb, and R. Reedy, Mat. Res. Soc. Symp. Proc. vol. 507, MRS, Warrendale, PA (1998) p. 447.

7. A. Terakawa, PhD Thesis, April (1999) Kyoto University, Kyoto Japan.

8. H. Matsumura, Mat. Res. Soc. Symp. Proc. vol. 118 (1988)

9. S. Dong, J. Liebe, Y. Tang, R. Braunstein, and B. von Roedern, NREL/SNL Photovoltaics Program Review Meeting, AIP Conf. Proc. 344 (1996) 537.

10. Y. Tang and R. Braunstein, J. Appl. Phys. 79 (1996) 850.

11. Y. Tang, S. Dong, R. Braunstein, and B. von Roedern, Appl. Phys. Lett. 68 (1996) 640.

12. S.R. Sheng, G.S. Sun, J. Liebe, A. Kattwinkel, R. Braunstein, B.P. Nelson, B. von Roedern, and K. Barner, Mat. Sci. Engin. A325 (2002) 490-496.

13. D.L. Williamson, Mat. Res. Soc. Symp. Proc. 377 (1995) 251.

14. J.A. Howard and R.A. Street, Phys. Rev. B 44, 7935 (1991).

15. G.Z. Yue, X.M. Deng, G. Ganguly, and D. Han, J. Non-Cryst. Solids, 266, part B (2000). 


\section{List of Table and Figure Captions}

Fig. 1: The photoconductivity of a-SiGe:H alloys as a function of the deposition rate. The dashed line represents typical PECVD results [3]; the solid line represents our results from HWCVD growth at high deposition rates [4].

Fig. 2: The photoconductivity (top frame, used in photomixing measurements), mobility (middle frame) and lifetime (bottom frame) of a-SiGe:H alloys as a function of the Tauc gap. The gray symbols $(\geq 1.4 \mathrm{eV})$ are from [12].

Fig. 3: The range (top frame) and depth (middle frame) of the potential fluctuations and the relative change in the density of charged defects (bottom frame) of a-SiGe:H alloys as a function of the Tauc gap. The gray symbols $(\geq 1.4 \mathrm{eV})$ are from [12].

Fig. 4: PL spectra at $80 \mathrm{~K}$ for samples L743, L744, and L745, (a) relative intensity and (b) normalized spectra.

Fig. 5: Light-induced effects on PL spectra for sample L745. The PL intensity increased about $30 \%$ from State A after light soaking by a $100 \mathrm{~mW} / \mathrm{cm} 2$ white light for 2 hours (State B1). There is little additional change with 2 more hours of light soaking (State B2).

Fig. 6: SAXS intensity for a-Si $i_{1-x} \mathrm{Ge}_{\mathrm{x}}: \mathrm{H}$ alloys with various $\mathrm{x}$, the values of which are given in parentheses. 
Fig. 7: The integrated SAXS intensity (top frame), photoresponse (middle frame) and Urbach energy (bottom frame) as a function of the Tauc gap. The dashed lines are the best data from [6].

Table 1: Deposition and PL summary data. All samples were grown with a 1:1 $\mathrm{H}_{2}$ dilution $(25 \mathrm{sccm})$

Table 2: Deposition, SAXS, and CPM summary data. All samples were grown with a 1:1 $\mathrm{H}_{2}$ dilution $(25 \mathrm{sccm})$ 
Figure 1
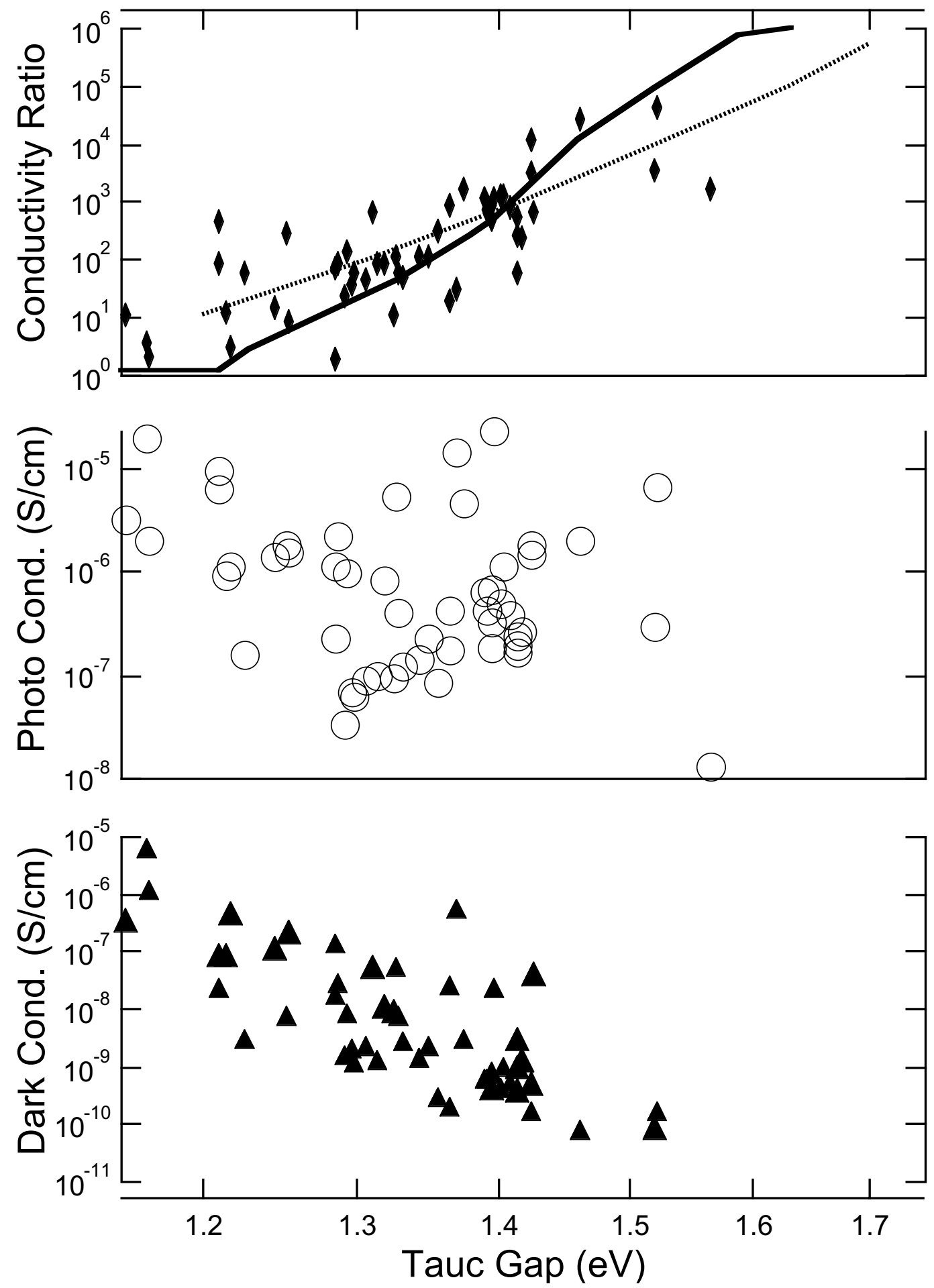
Figure 2
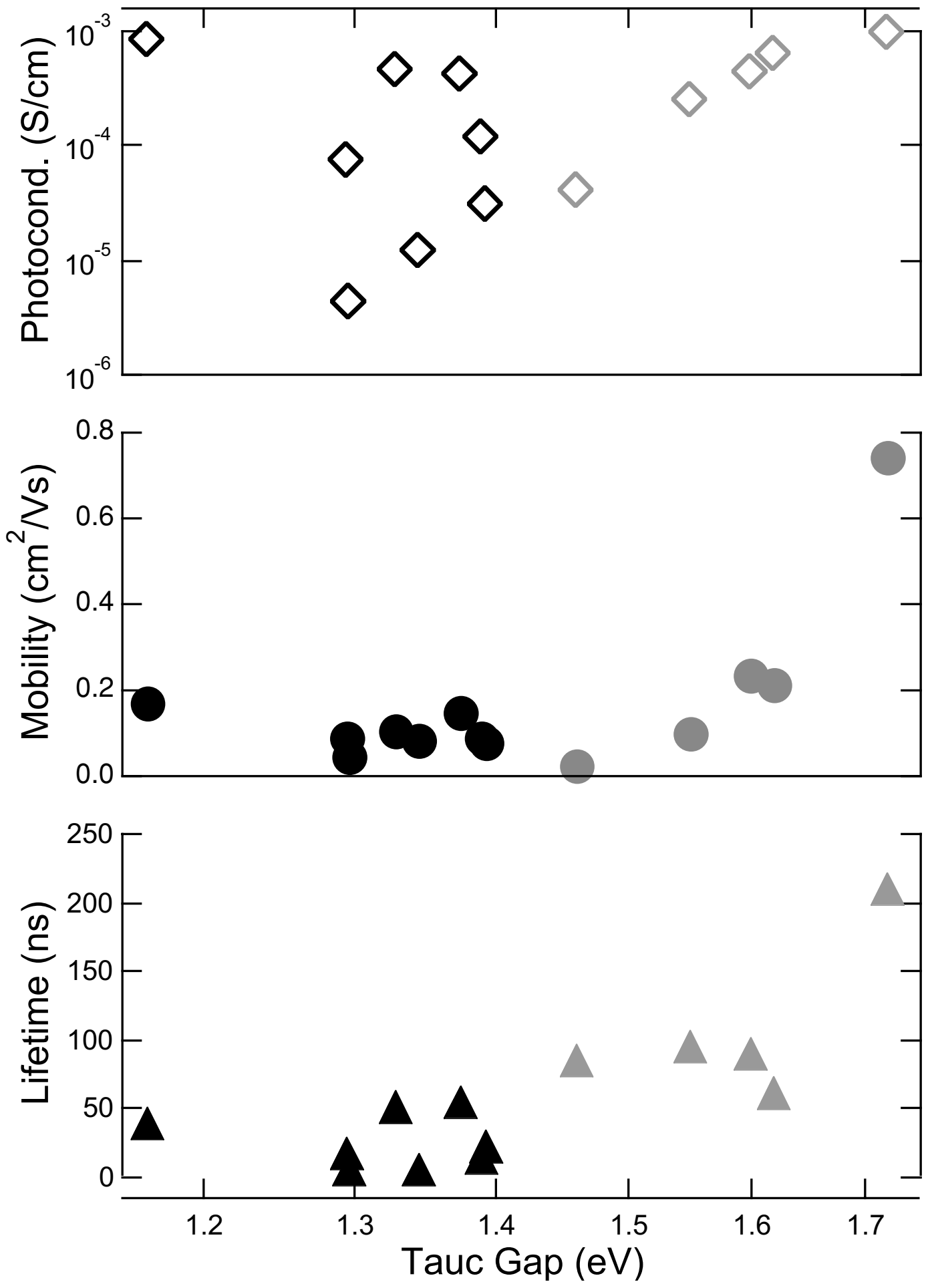
Figure 3
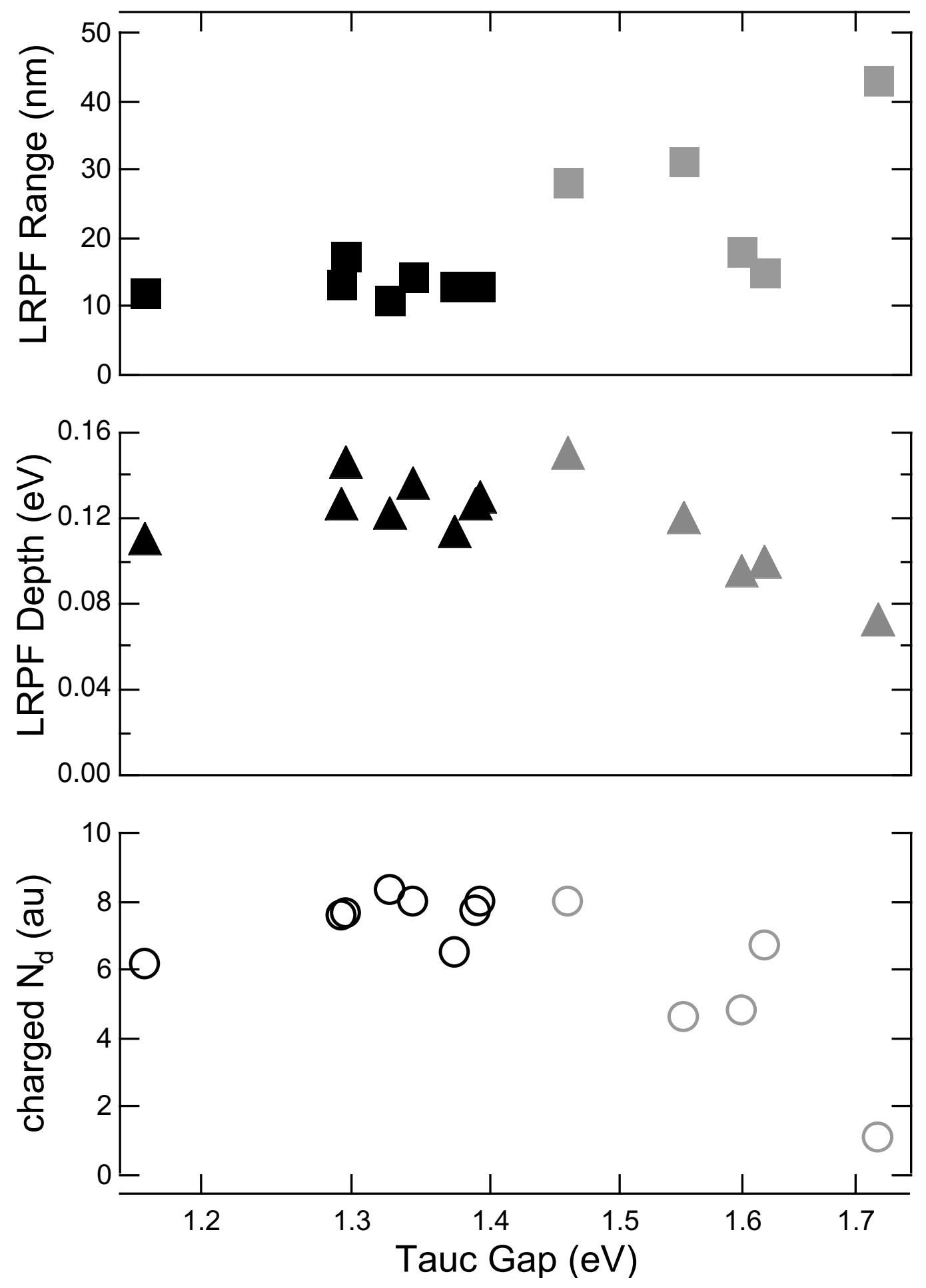
Figure 4
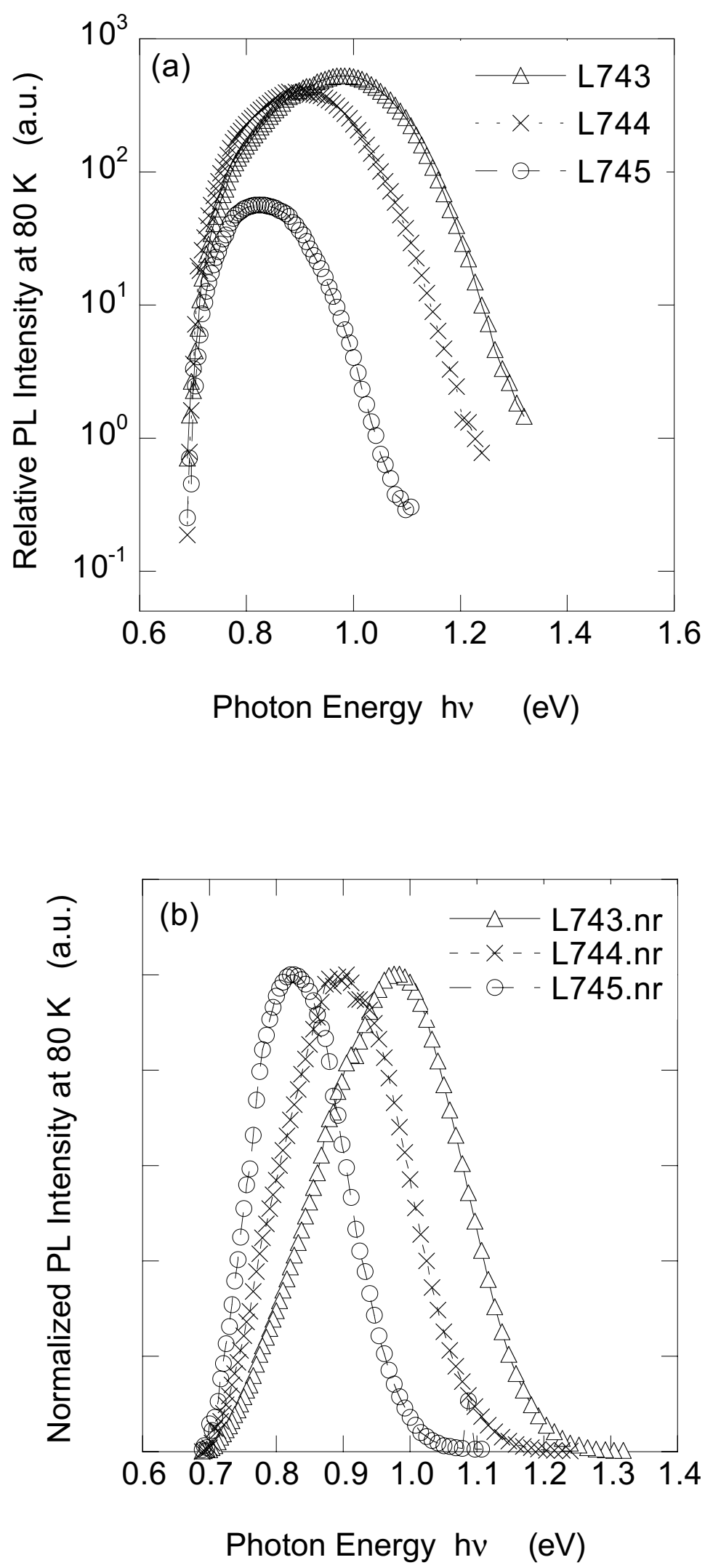
Figure 5

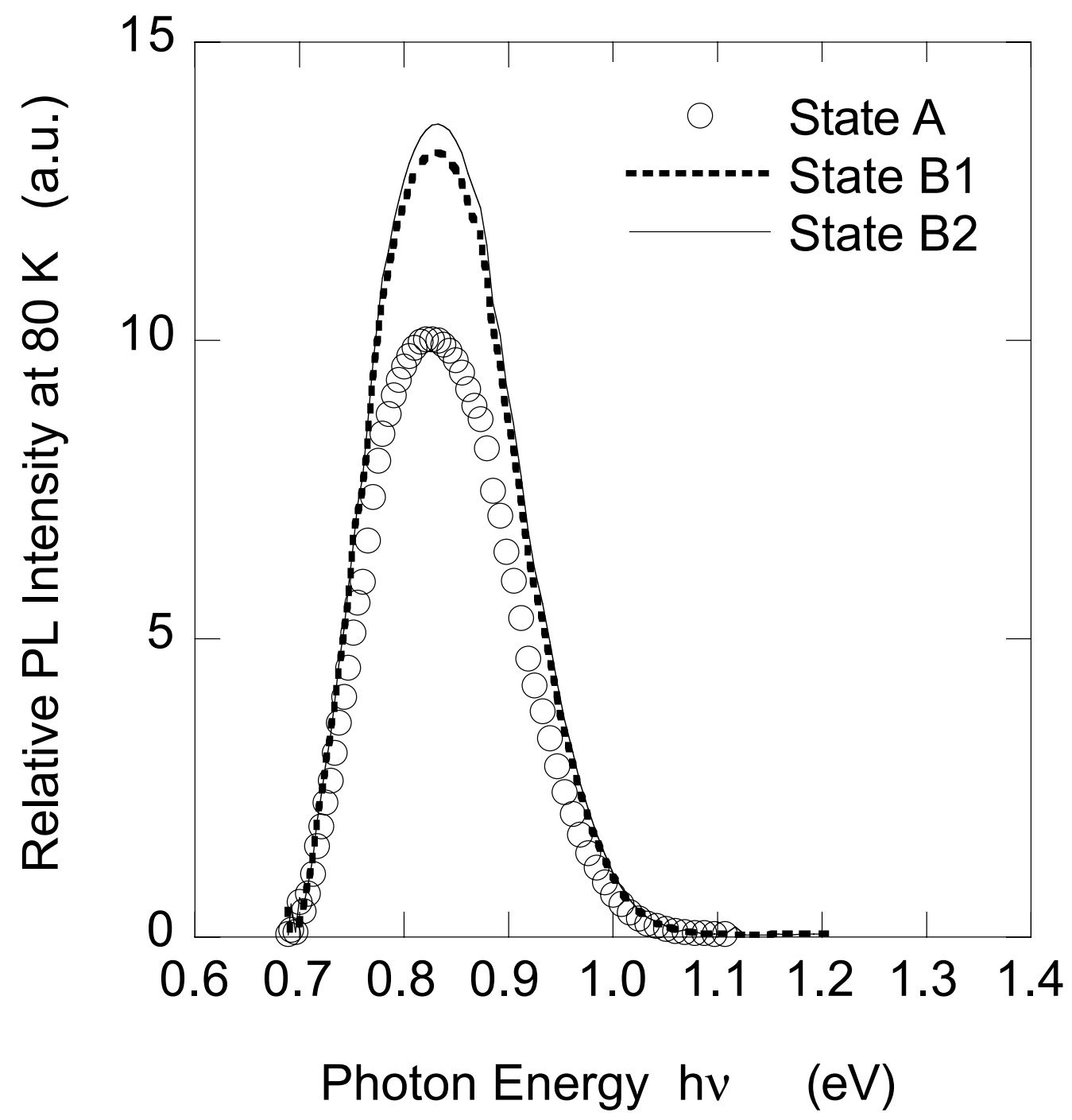


Figure 6

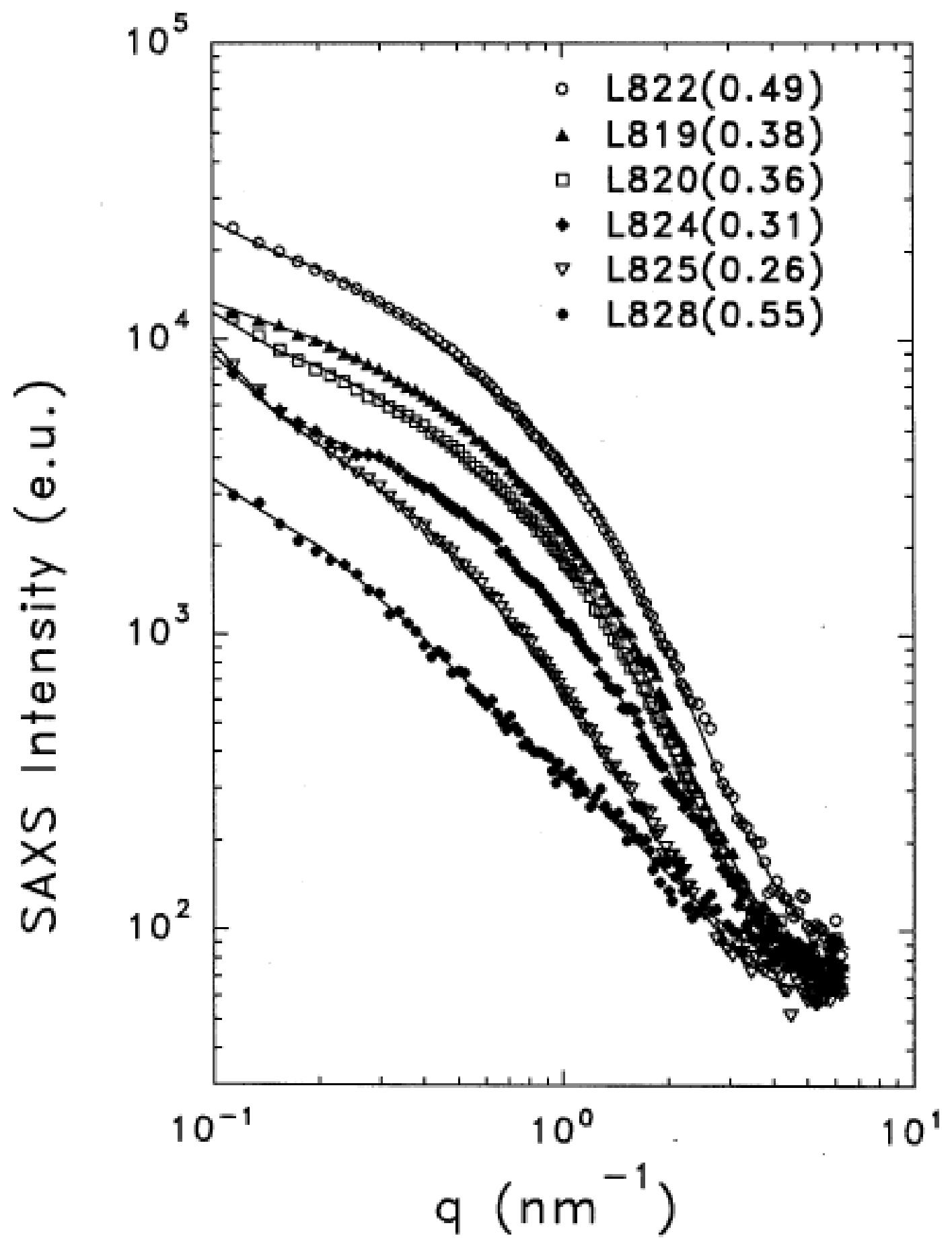


Figure 7
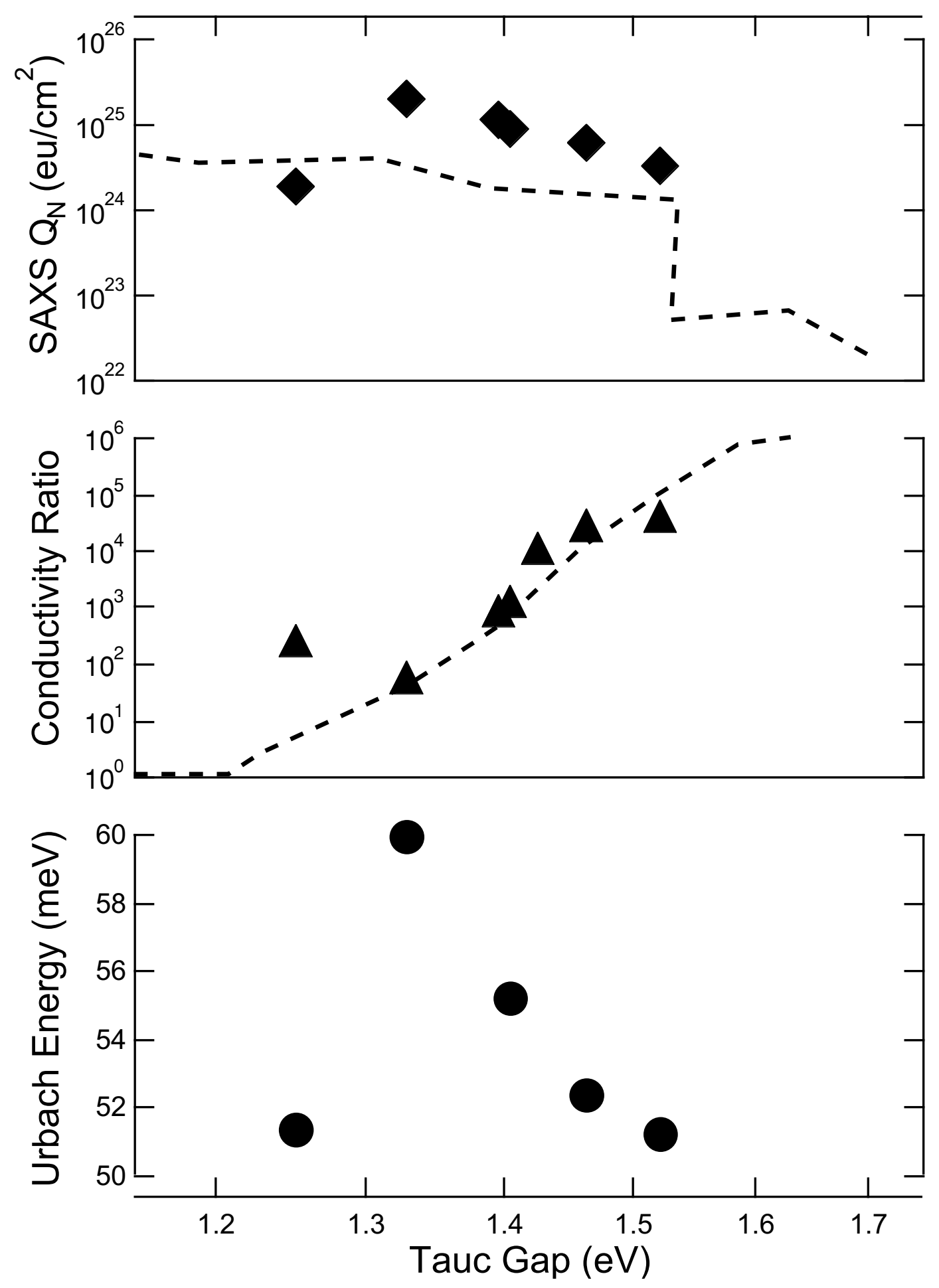
Table 1

\begin{tabular}{|l|c|c|c|}
\hline Sample & $\mathbf{L 7 4 3}$ & $\mathbf{L 7 4 4}$ & $\mathbf{L 7 4 5}$ \\
\hline Heater $\mathrm{T}\left({ }^{\circ} \mathrm{C}\right)$ & 250 & 250 & 125 \\
\hline $\mathrm{SiH}_{4} /\left(\mathrm{SiH}_{4}+\mathrm{GeH}_{4}\right)$ & 25 & 35 & 35 \\
\hline Filament $\mathrm{T}\left({ }^{\circ} \mathrm{C}\right)$ & 2150 & 2150 & 1800 \\
\hline Tauc gap $(\mathrm{eV})$ & 1.37 & 1.29 & 1.17 \\
\hline PL intensity & 550 & 400 & 22 \\
\hline PL peak E position $(\mathrm{eV})$ & 0.98 & 0.89 & 0.82 \\
\hline
\end{tabular}


Table 2

\begin{tabular}{|l|r|r|r|r|r|r|}
\hline Sample & L825 & L824 & L820 & L819 & L822 & L828 \\
\hline Heater T $\left({ }^{\circ} \mathrm{C}\right)$ & 250 & 250 & 250 & 250 & 250 & 150 \\
\hline $\mathrm{GeH}_{4} /\left(\mathrm{SiH}_{4}+\mathrm{GeH}_{4}\right)$ & 0.13 & 0.18 & 0.25 & 0.25 & 0.35 & 0.35 \\
\hline Filament $\mathrm{T}\left({ }^{\circ} \mathrm{C}\right)$ & 2100 & 2100 & 2100 & 2100 & 2100 & 1800 \\
\hline Deposition Rate $(\AA / \mathrm{A} / \mathrm{s})$ & 6.0 & 6.0 & 7.2 & 7.7 & 6.3 & 2.4 \\
\hline Tauc gap $(\mathrm{eV})$ & 1.52 & 1.46 & 1.40 & 1.40 & 1.33 & 1.25 \\
\hline Ge $($ at. $\%)$ by SIMS & 25.5 & 30.6 & 35.9 & 37.6 & 49.1 & 55.3 \\
\hline $\mathrm{Q}_{\mathrm{N}}\left(10^{24}\right.$ eu/cm $\left.{ }^{3}\right)$ by SAXS & 3.25 & 6.26 & 9.01 & 11.5 & 19.7 & 1.86 \\
\hline$<\mathrm{D}>(\mathrm{nm})$ by SAXS & 4.1 & 2.9 & 3.4 & 3.5 & 3.2 & 3.1 \\
\hline $\mathrm{E}_{\mathrm{u}}(\mathrm{meV})$ by CPM & 51 & 52 & 55 & & 60 & 53 \\
\hline
\end{tabular}




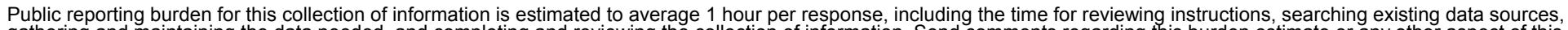

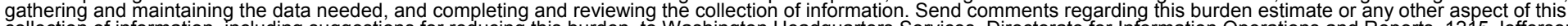
Washington Headquarters Services, Directorate for Information Operati

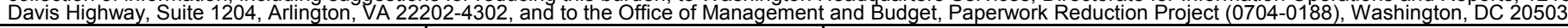
\begin{tabular}{l|l} 
1. AGENCY USE ONLY (Leave blank) & 2. REPORT DATE
\end{tabular}
August 2002
3. REPORT TYPE AND DATES COVERED
Conference Paper

4. TITLE AND SUBTITLE

Narrow Gap a-SiGe:H Grown by Hot-Wire Chemical Vapor Deposition: Preprint

6. AUTHOR(S)

B.P. Nelson, ${ }^{1}$ Y. Xu, ${ }^{1}$ D.L. Williamson, ${ }^{2}$ D. Han,${ }^{3}$ R. Braunstein, ${ }^{4}$ M. Boshta,${ }^{4}$ and B. Alavi ${ }^{4}$

7. PERFORMING ORGANIZATION NAME(S) AND ADDRESS(ES)

1. National Renewable Energy Laboratory, 1617 Cole Blvd., Golden, CO 80401-3393

2. Department of Physics, Colorado School of Mines, Golden, Colorado 80401

3. Physics Department \& Astronomy, University of North Carolina at Chapel Hill,

Chapel Hill, North Carolina 27599-3255

4. Department of Physics and Astronomy, University of California at Los Angeles, Los Angeles, California 90095

9. SPONSORING/MONITORING AGENCY NAME(S) AND ADDRESS(ES)

National Renewable Energy Laboratory

1617 Cole Blvd.

Golden, CO 80401-3393

5. FUNDING NUMBERS PVP34101

8. PERFORMING ORGANIZATION REPORT NUMBER

11. SUPPLEMENTARY NOTES

12a. DISTRIBUTION/AVAILABILITY STATEMENT

National Technical Information Service

12b. DISTRIBUTION CODE

U.S. Department of Commerce

5285 Port Royal Road

Springfield, VA 22161

13. ABSTRACT (Maximum 200 words: We have improved the quality of our narrow-bandgap a-SiGe:H grown by hot-wire chemical vapor deposition (HWCVD) by decreasing our W filament diameter and our substrate temperature. We now grow a-SiGe:H with Tauc bandgaps below $1.5 \mathrm{eV}$, having a photoresponse equal to or better than our plasma-enhanced CVD-grown alloys. We enhanced the transport properties_-as measured by the photoconductivity frequency mixing technique-relative to previous HWCVD results. These improved alloys do not necessarily show an improvement in the degree of structural heterogeneity on the nanometer scale, as measured by small-angle X-ray scattering. Decreasing both the filament temperature and substrate temperature produced a film with relatively low structural heterogeneity, while photoluminescence showed an order of magnitude increase in defect density for a similar change in the process.

14. SUBJECT TERMS: PV; germanium; alloy; hot-wire chemical vapor deposition (HWCVD); photoresponse; photoluminescence; small angle X-ray; a-SiGe:H; transport properties

15. NUMBER OF PAGES

17. SECURITY CLASSIFICATION OF REPORT Unclassified
18. SECURITY CLASSIFICATION OF THIS PAGE Unclassified
19. SECURITY CLASSIFICATION OF ABSTRACT Unclassified
16. PRICE CODE

20. LIMITATION OF ABSTRACT

UL 